\title{
Desempenho e Composição da Carcaça de Frangos de Corte Submetidos a Diferentes Períodos de Arraçoamento
}

\section{Renato Luis Furlan1*, João Guilherme de Camargo Ferraz Machado², Poliana Fernanda Giachetto $^{3}$, Euclides Braga Malheiros ${ }^{4}$, Luiz Roberto Furlan ${ }^{5}$, Marcos Macari ${ }^{1}$}

RESUMO - Este trabalho foi realizado com o objetivo de estudar a influência do período de arraçoamento sobre parâmetros zootécnicos, desenvolvimento visceral e composição da carcaça de frangos de corte. Foram utilizados 630 frangos da linhagem Cobb-500®, divididos em três programas de alimentação, a partir do $8^{\circ}$ até o $50^{\circ}$ dia de vida: ad libitum (AL - alimento durante 24 horas), arraçoamento diurno (AD - alimento à vontade das 7-19 h e restrito durante o período noturno 19-7 h) e arraçoamento noturno (AN - alimento à vontade das 19-7 h e restrito durante o período diurno 7-19h). A água foi fornecida à vontade para todos os grupos durante o período experimental. O período de arraçoamento ( 12 horas noturno ou diurno) reduziu significativamente o peso vivo final das aves. No entanto, aves arraçoadas durante o período noturno consumiram menos ração e mostraram melhor índice de conversão alimentar. O uso dos diferentes períodos de arraçoamento não afetou o desenvolvimento do fígado, moela, coração e comprimento do intestino. Aves arraçoadas por 12 horas, tanto no período noturno quanto no diurno, apresentaram maior teor de gordura na carcaça. O teor de cinzas não foi afetado pelo programa alimentar. Os resultados deste experimento sugerem que a adaptação ao novo programa alimentar foi muito lenta. Assim, as aves não foram capazes de manter o consumo de alimento compatível com seu desenvolvimento, ocorrendo com isso prejuízo no desempenho produtivo (peso vivo), bem como na composição da carcaça (gordura).

Palavras-chave: frangos de corte, desempenho, composição da carcaça, período de arraçoamento

\section{Performance and Carcass Composition of Broiler Chickens Submitted to Different Feeding Periods}

\begin{abstract}
This investigation was carried out to study the feeding period influence on broilers performance, viscera development, and carcass composition. A total of 630 broiler chickens, Cobb-500® strain, were allocated in three feeding programs from $8^{\text {th }}$ day to $50^{\text {th }}$ day of life: ad libitum (AL - food available 24 hours), diurnal feeding (DF - food provided ad libitum from 7 am to 7 pm and fed restricted from $7 \mathrm{pm}$ to $7 \mathrm{am}$ ) and nocturnal feeding (NF- food provided ad libitum from 7 pm to 7 am and fed restricted from 7 am to $7 \mathrm{pm}$ ). The water was provided ad libitum for all groups during experimental period. The feeding period (12 hours at nocturnal and diurnal) significantly decreased the broilers' final body weight. However, broilers fed at night showed lower feed intake and had better feed conversion index. The different feeding periods did not affect liver, gizzard, heart and intestine length development. Broilers fed for 12 hours during the night and during the day showed higher carcass fat content. Ash content was not affected by feeding program. The results suggested that the adaptation to feeding program was slow, thus, the broilers were not able to keep the feed consumption compatible with their development, with lower productive performance and higher carcass fat.
\end{abstract}

Key Words: broiler chickens, performance, carcass composition, diurnal and nocturnal feeding

\section{Introdução}

A alimentação do frango, além de corresponder a um alto percentual do custo de produção, é responsável por diversos processos que afetam o desenvolvimento das aves e, com isso, a viabilidade econômica. Assim, vários procedimentos têm sido pesquisados objetivando a melhoria do desempenho produtivo dos lotes de frangos. A restrição alimentar é uma das técnicas que vêm sendo adotadas e têm-se mostrado altamente eficaz em melhorar algumas características produtivas dos frangos. Plavnik et al. (1986) e Giachetto (1998) relataram que a restrição alimentar em idade precoce e por curto período de tempo mostrou-se eficaz em melhorar a eficiência/conversão alimentar e reduzir a quantidade de gordura na carcaça de frangos de corte. Já Gonzales et al.

\footnotetext{
${ }^{1}$ Professores Depto. de Morfologia e Fisiologia Animal - Faculdade de Ciências Agrárias e Veterinárias - Via de Acesso Prof. Paulo Donato Castelane s/n - 14.884-900 Jaboticabal- SP - Brasil. E.mail: rlfurlan@fcav.unesp.br; macari@fcav.unesp.br

2 Aluno de Graduação do curso de Zootecnia da FCAVAJNESP

${ }^{3}$ Doutoranda da FCAV/UNESP. E.mail: poferg @fcav.u esp.br

4 Professor Depto. de Cências Exatas da FCA /UNESF. E.mail: euclides@fcav.unesp.br

5 Professor Depto. de Melhoramento e Nutriçã Animal la FMVZ/UNESP. E.mail: cedral@fcav.unesp.br
} 
(1998) observaram eficácia da restrição alimentar em reduzir a ocorrência de síndromes metabólicas, como ascite e morte súbita.

Uma das preocupações com relação à introdução da técnica de restrição alimentar está relacionada ao ganho compensatório, pois o peso corporal do frango, na época do abate, ainda é parâmetro importante para comercialização. No entanto, vários trabalhos têm mostrado que, após a restrição, o frango de corte apresenta ganho compensatório em relação às aves alimentadas à vontade. Por outro lado, a recuperação total ou parcial do peso perdido durante a restrição alimentar dependerá de vários fatores, entre eles: sexo, natureza (qualitativa ou quantitativa), severidade da restrição, linhagem e idade do frango (Wilson \& Osbourn, 1960; Yu \& Robinson, 1992).

Gonzales et al. (1998) mostraram que frangos foram capazes de apresentar ganho compensatório após o período de restrição alimentar realizada entre o oitavo e o décimo quarto dias de idade. Resultados semelhantes foram encontrados por Susbilla et al. (1994). Entretanto, Yu et al. (1990) e Robinson et al. (1992) não observaram ganho compensatório, após um período de restrição alimentar, sugerindo que o mesmo não existe.

Considerando que os trabalhos acima citados foram realizados com restrição alimentar quantitativa, limitando o comportamento alimentar das aves, a proposta desta investigação não foi estabelecer regime de restrição aos frangos, mas sim submeter as aves a uma forma diferente de arraçoamento. Assim, durante o período de alimentação (noturno ou diurno), as aves poderiam ingerir e armazenar quantidades de alimento de acordo com suas exigências fisiológicas. A hipótese deste experimento foi a de que as aves teriam capacidade de ingerir e armazenar quantidades de alimento compatíveis ao seu desenvolvimento, sem prejuízo do desempenho produtivo, quando arraçoadas em período diurno ou noturno.

\section{Material e Métodos}

O experimento foi conduzido no Aviário Experimental da Faculdade de Ciências Agrárias e Veterinárias, Campus de Jaboticabal, sendo utilizados 630 pintos de corte machos da linhagem Cobb-500®, criados de 1 a 50 dias de idade. As aves foram alojadas em galpão convencional de alvenaria, dividido em boxes de $1,50 \mathrm{~m}$ de largura x $2,50 \mathrm{~m}$ de comprimento, tendo maravalha de pínus como cama.
Cada divisão estava equipada com bebedouros pendulares automáticos e comedouros tubulares. A temperatura ambiente média, durante o experimento, foi de $22,6^{\circ} \mathrm{C}$ (temperatura mínima de $15,6^{\circ} \mathrm{C}$ e máxima de $29,6^{\circ} \mathrm{C}$ ) e umidade relativa do ar de $63,2 \%$ (Estação Agroclimatológica, Depto. de Ciências Exatas da FCAV/UNESP- Campus de Jaboticabal, Latitude: $21^{\circ} 15^{\prime} 22^{\prime}$ 'S, Longitude: $48^{\circ} 18^{\prime} 58^{\prime}{ }^{\prime} \mathrm{W}$, Altitude:595m).

Do primeiro ao sétimo dia de idade, todas as aves consumiram ração ad libitum. A partir do $8^{\circ}$ até $50^{\circ}$ dia de vida, as aves foram submetidas a três diferentes períodos de arraçoamento: ad libitum (AL - alimento durante 24 horas), arraçoamento diurno (AD - alimento à vontade das 7 às $19 \mathrm{~h}$ e restrito durante o período noturno das 19 às $7 \mathrm{~h}$ ) e arraçoamento noturno (AN - alimento à vontade das 19 às $7 \mathrm{~h}$ e restrito durante o período diurno das 7 às $19 \mathrm{~h}$ ). A água foi fornecida à vontade para as aves em todos os tratamentos durante todo o período experimental. O programa de iluminação adotado forneceu luz durante 24 horas. Foram formuladas duas rações, tendo como base milho e farelo de soja como componentes energético e protéico, além da adição de suplemento vitamínico-mineral (Tabela 1 ).

No $21^{\circ}, 35^{\circ}$ e $50^{\circ}$ dia de idade, foram retiradas, ao acaso, nove aves de cada tratamento, as quais foram submetidas a jejum alimentar de 1 hora e, posteriormente, sacrificadas por deslocamento cervical, depenadas e, em seguida, dissecadas. A moela foi aberta e o conteúdo removido com papeltoalha seco, sendo o peso obtido após esse procedimento. O fígado e o coração foram removidos e pesados imediatamente. Para evitar efeito da ingesta, o conteúdo intestinal foi retirado comprimindo-se os intestinos com os dedos no início do duodeno em direção à cloaca, sendo o peso obtido após esse procedimento. $\mathrm{O}$ intestino também foi medido desde o início do duodeno até a cloaca. Para as análises laboratoriais, a carcaça mais as vísceras, cabeça e pés (excluindo-se as penas) de cada ave foram moídas, secas em estufa com ventilação forçada a $55^{\circ} \mathrm{C}$ por 72 horas e, posteriormente, trituradas em moinho de faca (tamanho médio das partículas $1 \mathrm{~mm}$ ). $\mathrm{O}$ teor de proteína foi obtido pelo método de Microkjeldahl (LANARA, 1981) e a determinação do extrato etéreo das carcaças foi realizada pelo método de Soxhlet (LANARA, 1981).

O delineamento experimental utilizado foi o inteiramente ao acaso, com nove repetições por trata-

R. Bras. Zootec., v.31, n.6, p.2265-2273, 2002 
Tabela 1 - Composição das dietas experimentais

Table 1 - Composition of the experimental diets

\begin{tabular}{|c|c|c|}
\hline \multirow[t]{2}{*}{$\begin{array}{l}\text { Ingredientes (\%) } \\
\text { Ingredients }\end{array}$} & \multicolumn{2}{|c|}{$\begin{array}{l}\text { Ração } \\
\text { Ration }\end{array}$} \\
\hline & $\begin{array}{c}\text { Inicial (1-28 dias) } \\
\text { Starter diet (1-28days) }\end{array}$ & $\begin{array}{l}\text { Crescimento (29-50 dias) } \\
\text { Growing diet (29-50 days) }\end{array}$ \\
\hline Milho moído & 48,15 & 54,44 \\
\hline $\begin{array}{l}\text { Corn grain } \\
\text { Farelo de soja } \\
\text { Soybean meal }\end{array}$ & 39,26 & 33,70 \\
\hline $\begin{array}{l}\text { Óleo de soja } \\
\text { Soybean oil }\end{array}$ & 7,50 & 6,50 \\
\hline $\begin{array}{l}\text { Núcleo* } \\
\text { Vitmin mix }\end{array}$ & 5,00 & 5,00 \\
\hline $\begin{array}{l}\text { Material inerte } \\
\text { Inert material }\end{array}$ & 0,08 & 0,35 \\
\hline $\begin{array}{l}\text { BHT } \\
\text { Total }\end{array}$ & $\begin{array}{r}0,01 \\
100,00\end{array}$ & $\begin{array}{r}0,01 \\
100,00\end{array}$ \\
\hline $\begin{array}{l}\text { Valores calculados } \\
\text { Calculated composition }\end{array}$ & & \\
\hline $\begin{array}{l}\text { Proteína bruta }(\%) \\
\text { Crude protein }\end{array}$ & 22,00 & 20,00 \\
\hline $\begin{array}{l}\text { Energia metabolizável }(\mathrm{kcal} / \mathrm{kg}) \\
\text { Metabolizable energy }\end{array}$ & 3200 & 3200 \\
\hline $\begin{array}{l}\text { Metionina (\%) } \\
\text { Methionine }\end{array}$ & 0,42 & 0,39 \\
\hline $\begin{array}{l}\text { Metionina }+ \text { cistina }(\%) \\
\text { Met }+ \text { Cys }\end{array}$ & 0,70 & 0,64 \\
\hline $\begin{array}{l}\text { Lisina }(\%) \\
\text { Lysine }\end{array}$ & 1,24 & 1,09 \\
\hline $\begin{array}{l}\text { Cálcio }(\%) \\
\text { Calcium }\end{array}$ & 1,03 & 1,01 \\
\hline $\begin{array}{l}\mathrm{P} \text { disponível }(\%) \\
\text { Available phosphorus }\end{array}$ & 0,45 & 0,45 \\
\hline 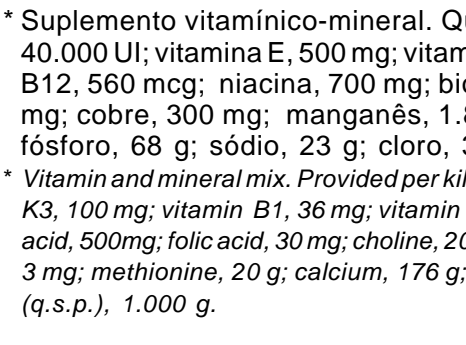 & $\begin{array}{l}\text { antidade suprida por } \mathrm{kg} \mathrm{d} \\
\text { na K3, } 100 \mathrm{mg} \text {; vitamina B1 } \\
\text { tina, } 3 \mathrm{mg} \text {; ácido pantotêni } \\
00 \mathrm{mg} \text {; zinco, } 1.200 \mathrm{mg} \text {; io } \\
6 \mathrm{~g} \text {; coccidiostático, } 10 \mathrm{~g} \\
\text { gram of product (premix): vitan } \\
32,200 \mathrm{mg} \text {; vitamin } \mathrm{B} 6,50 \mathrm{mg} \text {; } \\
\text { g; iron, } 1.100 \mathrm{mg} \text {; cooper, } 300 \mathrm{n} \\
\text { hosphorus, } 68 \text { g; sodium, } 23\end{array}$ & $\begin{array}{l}\text { ina A, } 176.000 \mathrm{Ul} \text {; vitamina D3, } \\
\text { mg; vitamina B6, } 50 \mathrm{mg} \text {; vitamina } \\
30 \mathrm{mg} \text {; colina, } 20 \mathrm{~g} \text {; ferro, } 1.100 \\
\text {; metionina, } 20 \mathrm{~g} \text { cálcio, } 176 \mathrm{~g} \text {; } \\
\text { oiente (q.s.p.), } 1.000 \mathrm{~g} \text {. } \\
40.000 \mathrm{IU} \text {; vitamin } \mathrm{E}, 500 \mathrm{mg} \text {; vitamin } \\
\text { in, } 700 \mathrm{mg} \text {; biotin, } 3 \mathrm{mg} \text {; pantothenic } \\
\text { nc, } 1.200 \mathrm{mg} \text {; iodine, } 24 \mathrm{mg} \text {; selenium, } \\
\text { tatic, } 10 \mathrm{~g} \text {; antioxidant, } 1 \mathrm{~g} \text {; excipient }\end{array}$ \\
\hline
\end{tabular}

mento, segundo um esquema em parcelas subdivididas, tendo como parcelas os tratamentos (ad libitum, alimentação diurna e alimentação noturna) e, como subparcelas, a idade das aves (dias). A análise de variância foi realizada pelo procedimento GLM do SAS (2000) e a significância entre as médias comparada pelo teste Tukey.

\section{Resultados e Discussão}

Embora os mecanismos compensatórios sejam considerados inerentes ao crescimento de todos os organismos biológicos, as reações compensatórias, de qualquer natureza, não são propriedades fixas dos organismos ou tecidos, mas são dependentes de fatores como: duração da restrição alimentar, período de realimentação, idade, sexo e temperatura ambiente. Os valores da Tabela 2 indicam que para o peso vivo, ganho de peso e consumo de ração houve interação significativa $(\mathrm{P}<0,01)$ entre o programa de alimentação e a idade das aves. O desdobramento da interação (Tabela 3 ) mostra que a idade influenciou $(\mathrm{P}<0,01) \mathrm{o}$ peso vivo, o ganho de peso e o consumo de ração, ocorrendo aumento dos valores dessas variáveis em função do crescimento das aves, independente do programa alimentar. Com relação ao efeito do programa alimentar, verificou-se que, aos 50 dias de idade, o peso vivo dos animais arraçoados tanto no

R. Bras. Zootec., v.31, n.6, p.2265-2273, 2002 
Tabela 2 - Efeitos do período de arraçoamento e da idade sobre os parâmetros zootécnicos dos frangos. Cada valor representa a média \pm SEM

Table 2 - Effects of feeding program and age on performance parameters of broilers. Each value represents the mean \pm SEM

\begin{tabular}{|c|c|c|c|c|c|}
\hline \multirow[t]{2}{*}{$\begin{array}{l}\text { Programa alimentar } \\
\text { Feeding program }\end{array}$} & \multicolumn{5}{|c|}{$\begin{array}{l}\text { Parâmetros } \\
\text { Parameters }\end{array}$} \\
\hline & $\begin{array}{l}\text { Peso vivo }(\mathrm{g}) \\
\text { Body weight }\end{array}$ & $\begin{array}{c}\text { Ganho } \\
\text { de peso (g) } \\
\text { Bodyweight gain }\end{array}$ & $\begin{array}{c}\text { Consumo } \\
\text { de ração }(\mathrm{g}) \\
\text { Feed consumption }\end{array}$ & $\begin{array}{c}\text { Conversão alimentar } \\
\text { total }(\%) \\
\text { Feed conversion }\end{array}$ & $\begin{array}{l}\text { Mortalidade } \\
\text { Total mortality }\end{array}$ \\
\hline Ad libitum & $1717 \pm 230$ & $927 \pm 81$ & $1780 \pm 118$ & $1,88 \pm 0,04^{\mathrm{a}}$ & $4,76 \pm 1,59^{a}$ \\
\hline $\begin{array}{l}\text { Arraçoamento noturno } \\
\text { Nocturnalfeeding }\end{array}$ & $1545 \pm 213$ & $857 \pm 83$ & $1501 \pm 174$ & $1,69 \pm 0,04^{\mathrm{b}}$ & $0,0 \pm 0,00^{\mathrm{b}}$ \\
\hline $\begin{array}{l}\text { Arraçoamento diurno } \\
\text { Diurnal feeding } \\
\text { Idade (dias) } \\
\text { Age (days) }\end{array}$ & $1545 \pm 219$ & $858 \pm 89$ & $1616 \pm 192$ & $1,84 \pm 0,03^{\mathrm{a}}$ & $1,00 \pm 0,60^{\mathrm{b}}$ \\
\hline $\begin{array}{l}21 \\
35 \\
50\end{array}$ & $\begin{array}{c}535 \pm 10 \\
1518 \pm 23 \\
2755 \pm 32\end{array}$ & $\begin{array}{c}415 \pm 10 \\
990 \pm 23 \\
1237 \pm 15\end{array}$ & $\begin{array}{c}700,15 \pm 22 \\
1685,08 \pm 47 \\
2511,54 \pm 37\end{array}$ & $\begin{array}{l}1,69 \pm 0,03^{\mathrm{b}} \\
1,70 \pm 0,02^{\mathrm{b}} \\
2,03 \pm 0,03^{\mathrm{a}}\end{array}$ & $\begin{array}{c}0,31 \pm 0,32^{\mathrm{ab}} \\
0,16 \pm 0,15^{\mathrm{b}} \\
1,43 \pm 0,53^{\mathrm{a}}\end{array}$ \\
\hline $\begin{array}{l}\text { Probabilidades } \\
\text { Probabilities }\end{array}$ & & & & & \\
\hline $\begin{array}{l}\text { Programa alimentar }(\mathrm{PA}) \\
\text { Feeding program }(F P)\end{array}$ & $<0,01$ & $<0,01$ & $<0,01$ & $<0,01$ & $<0,01$ \\
\hline $\begin{array}{l}\text { Idade }(\mathrm{I}) \\
\text { Age }(A)\end{array}$ & $<0,01$ & $<0,01$ & $<0,01$ & $<0,01$ & 0,01 \\
\hline $\begin{array}{l}\mathrm{PA} \times \mathrm{I} \\
F P \times A\end{array}$ & $<0,01$ & $<0,01$ & $<0,01$ & NS & NS \\
\hline
\end{tabular}

a,b Médias seguidas por letras diferentes, nas colunas, diferem entre si pelo teste Tukey.

a,b Means within a column with no common superscript differ significantly by Tukey test.

Tabela 3 - Interações entre período de arraçoamento e idade sobre o peso vivo, ganho de peso e consumo de ração. Cada valor representa a média \pm SEM

Table 3 - Interactions between feeding program and age on body weight, body weight gain and feed intake. Each value represents the mean \pm SEM

\begin{tabular}{|c|c|c|c|c|}
\hline \multirow[t]{2}{*}{$\begin{array}{l}\text { Parâmetros } \\
\text { Parameters }\end{array}$} & \multirow[t]{2}{*}{$\begin{array}{l}\text { Programa alimentar } \\
\text { Feeding program }\end{array}$} & \multicolumn{3}{|c|}{$\begin{array}{l}\text { Idade (dias) } \\
\text { Age (days) }\end{array}$} \\
\hline & & 21 & 35 & 50 \\
\hline \multirow{4}{*}{$\begin{array}{l}\text { Peso vivo (g) } \\
\text { Body weight }\end{array}$} & Ad libitum & $579 \pm 10^{\mathrm{Ca}}$ & $1673 \pm 33^{\mathrm{Ba}}$ & $2897 \pm 36^{\mathrm{Aa}}$ \\
\hline & $\begin{array}{l}\text { Arraçoamento noturno } \\
\text { Nocturnalfeeding }\end{array}$ & $531 \pm 19^{\mathrm{Ca}}$ & $1437 \pm 23^{\mathrm{Bb}}$ & $2668 \pm 49^{\mathrm{Ab}}$ \\
\hline & $\begin{array}{l}\text { Arraçoamento diurno } \\
\text { Diurnalfeeding }\end{array}$ & $494 \pm 10^{\mathrm{Ca}}$ & $1443 \pm 19^{\mathrm{Bb}}$ & $2699 \pm 26^{\mathrm{Ab}}$ \\
\hline & Ad libitum & $462 \pm 11^{\mathrm{Ca}}$ & $1095 \pm 27^{\mathrm{Ba}}$ & $1223 \pm 19^{\mathrm{Aa}}$ \\
\hline \multirow{2}{*}{$\begin{array}{l}\text { Ganho de peso }(\mathrm{g}) \\
\text { Body weight gain }\end{array}$} & Arraçoamento noturno & $414 \pm 20^{\mathrm{Cb}}$ & $925 \pm 31^{\mathrm{Bb}}$ & $1231 \pm 37^{\mathrm{Aa}}$ \\
\hline & $\begin{array}{c}\text { Nocturnalfeeding } \\
\text { Arraçoamento diurno } \\
\text { Diurnal feeding }\end{array}$ & $367 \pm 8^{\mathrm{Cb}}$ & $949 \pm 20^{\mathrm{Bb}}$ & $1257 \pm 20^{\mathrm{Aa}}$ \\
\hline \multirow{3}{*}{$\begin{array}{l}\text { Consumo de ração }(\mathrm{g}) \\
\text { Feed intake }\end{array}$} & Ad libitum & $824 \pm 13^{\mathrm{Ca}}$ & $1931 \pm 35^{\mathrm{Ba}}$ & $2586 \pm 53^{\mathrm{Aa}}$ \\
\hline & Arraçoamento noturno & $630 \pm 8^{\mathrm{Cb}}$ & $1498 \pm 18^{\mathrm{Bc}}$ & $2375 \pm 56^{\mathrm{Ab}}$ \\
\hline & $\begin{array}{c}\text { Nocturnalfeeding } \\
\text { Arraçoamento diurno } \\
\text { Diurnal feeding }\end{array}$ & $647 \pm 12^{\mathrm{Cb}}$ & $1627 \pm 32^{\mathrm{Bb}}$ & $2573 \pm 48^{\mathrm{Aa}}$ \\
\hline
\end{tabular}

aA-cC Médias seguidas por letras minúsculas (maiúsculas) diferentes, nas colunas (linhas), diferem entre si pelo teste Tukey. aA-cC Means followed by small (capital) letter in the same column (lines) differ significantly by Tukey test. 
período diurno, quanto noturno, foi menor $(\mathrm{P}<0,01)$ que o dos animais alimentados ad libitum. Os grupos arraçoados nos períodos diurno e noturno apresentaram menor ganho de peso até os 35 dias de idade, porém não foram observadas diferenças significativas $(\mathrm{P}>0,01)$ entre esses tratamentos aos 50 dias de idade (Tabela 3 ).

Observações de Plavnik \& Hurwitz (1985) indicaram que o ganho compensatório é maior após um curto período de restrição alimentar. Intervalos longos sem a quantidade suficiente de nutrientes pode resultar em um atraso ou provocar danos permanentes na recuperação do peso corporal (Sklan et al., 2000). No entanto, Zubair \& Leeson (1994) verificaram que, quanto mais descontínuo o período de alimentação, maior é a habilidade da ave em aumentar o consumo de ração. Segundo Barash et al. (1993), frangos aprendem rapidamente a ingerir quantidades de alimento em um curto período de tempo, quando o acesso ao alimento é limitado. Os resultados deste trabalho, entretanto, mostraram que o programa alimentar afetou $(\mathrm{P}<0,01) \mathrm{o}$ consumo de ração, sendo observado que animais arraçoados no período noturno consumiram $(\mathrm{P}<0,01)$ menos ração do que as aves arraçoadas ad libitum ou no período diurno (Tabela 3), sugerindo que as aves alimentadas no período noturno apresentaram uma adaptação lenta ao novo tipo de arraçoamento. Buyse et al. (1993) também observaram menor consumo de ração durante a noite em frangos de corte.

Um dos índices zootécnicos que melhor retratam o desempenho do frango é a conversão alimentar. Vários trabalhos têm mostrado uma melhora na eficiência de utilização dos nutrientes em frangos após o período de restrição alimentar (Zubair \& Leeson, 1996; Giachetto, 1998). Entretanto, Plavnik \& Hurwtiz (1991) verificaram melhor conversão alimentar apenas durante o período de restrição, e Susbilla et al. (1994) não encontraram melhora na conversão alimentar em frangos restritos. Foi observado, neste experimento, que aves arraçoadas no período noturno apresentaram melhor conversão alimentar, diferindo $(\mathrm{P}<0,01)$ dos animais arraçoados ad libitum ou no período diurno, os quais não diferiram $(\mathrm{P}>0,05)$ entre si. Os dados da Tabela 2 mostram também uma melhor conversão alimentar $(\mathrm{P}<0,01)$ nas aves até o $35^{\circ}$ dia de idade. $\mathrm{O}$ manejo alimentar adotado para esse grupo, alimentação noturna e restrição diurna, pode ter favorecido o melhor aproveitamento alimentar, por meio do menor gasto energético para manutenção da homeotermia. No entanto, mesmo apresentando uma melhor conversão alimentar, aves mantidas nesse regime de arraçoamento apresentaram peso vivo $(\mathrm{P}<0,01)$ menor do que aves alimentadas ad libitum aos 50 dias de idade.

Estudos têm mostrado que menor taxa de crescimento, durante a fase jovem do frango de corte, pode reduzir a mortalidade (Robinson et al., 1992). Os dados de mortalidade deste experimento (Tabela 2) mostram que aves arraçoadas por um período de 12 horas, tanto diurno quanto noturno, também tiveram uma redução significativa $(\mathrm{P}<0,01)$ na mortalidade total, quando comparadas ao grupo alimentado ad libitum. Resultados semelhantes foram encontrados por Lippens et al. (2000), que observaram redução na incidência de mortalidade em frangos submetidos à restrição alimentar quantitativa. Apesar do percentual de mortalidade demonstrar efeito benéfico sobre a viabilidade das aves, o consumo de ração, nos diferentes períodos de arraçoamento estudados, determinou uma redução significativa $(\mathrm{P}<0,01)$ no peso final dos frangos. No entanto, Gonzales et al. (1998) observaram que a restrição alimentar quantitativa de $30 \%$ a $40 \%$ reduziram a mortalidade de frangos, sem prejuízo produtivo, desde que seguida de pelo menos três semanas de plena alimentação.

O crescimento, bem como o desenvolvimento das funções secretoras e absortivas do trato gastrintestinal, estão na dependência da disponibilidade de nutrientes. Além disto, a manutenção do crescimento do trato digestório tem grande contribuição na eficiência dos processos digestivos. Cherry \& Siegel (1978) observaram que frangos com trato digestivo mais pesado apresentaram menor velocidade de esvaziamento gastrointestinal, permitindo assim uma maior exposição dos nutrientes às células absortivas, com conseqüente influência na utilização dos alimentos. Os resultados da Tabela 4 revelam que o peso relativo do fígado, da moela, do coração e o comprimento do intestino não foram afetados $(\mathrm{P}>0,05)$ pelo período de alimentação. No entanto, foi observado interação $(\mathrm{P}<0,01)$ entre o programa de alimentação e a idade das aves para o peso do intestino e rendimento de carcaça (Tabela 4). A análise da interação (Tabela 5) mostrou que, independentemente do programa alimentar, houve redução $(\mathrm{P}<0,01)$ no peso relativo do intestino com o crescimento das aves. Quanto ao efeito do programa alimentar, foi verificado que, a partir do $35^{\circ}$ dia, as aves arraçoadas no período noturno apresentaram peso relativo de intestino $(\mathrm{P}<0,01)$ maior que o das aves alimentadas ad libitum ou arraçoadas no período diurno.

\section{R. Bras. Zootec., v.31, n.6, p.2265-2273, 2002}


Tabela 4 - Efeitos do período de arraçoamento e da idade sobre o desenvolvimento visceral e rendimento de carcaça dos frangos. Cada valor representa a média \pm SEM

Table 4 - Effects of feeding program and age on viscera development and carcass yield of broilers. Each value represents the mean \pm SEM

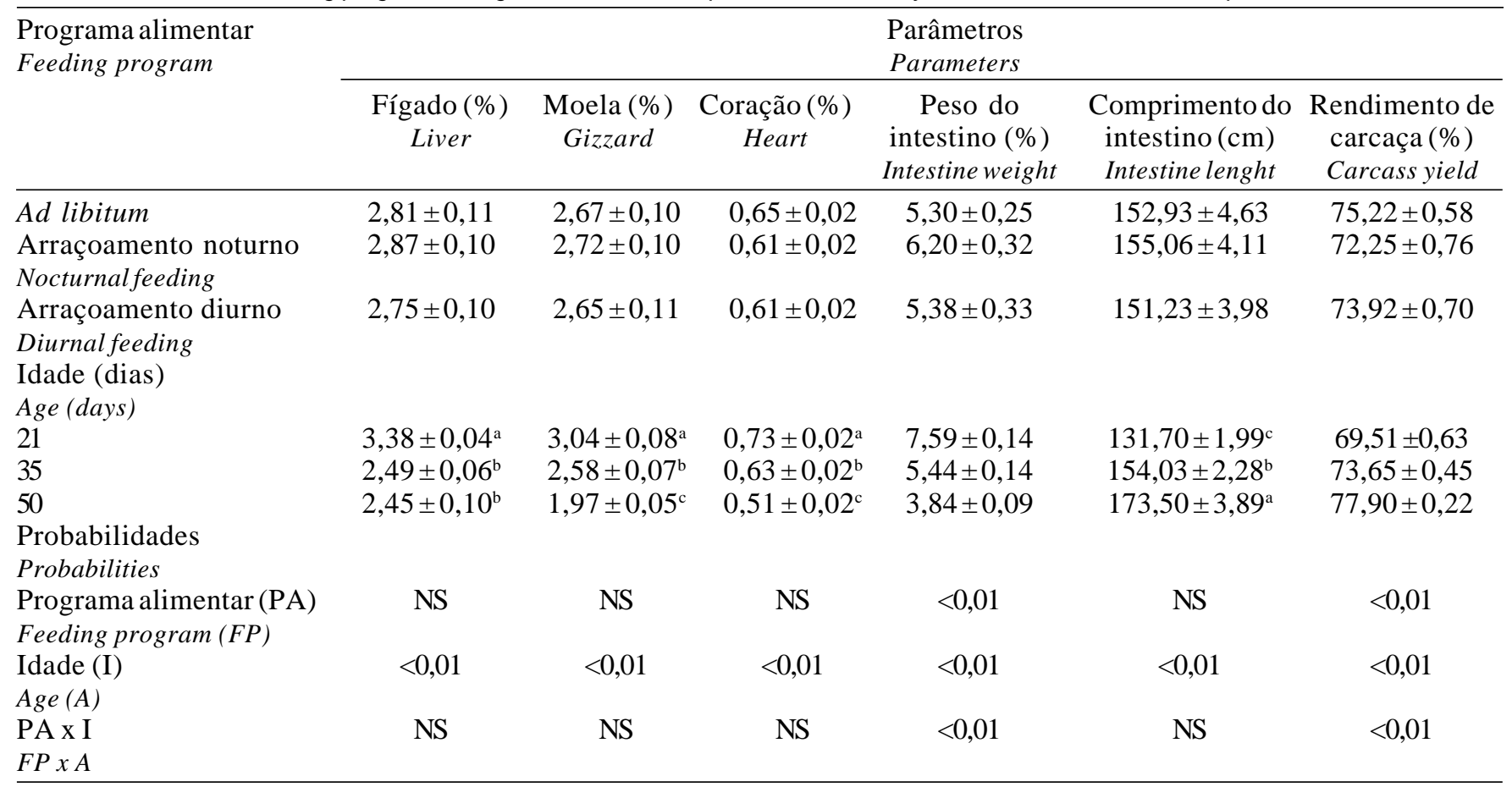

a, c Médias seguidas por letras diferentes, nas colunas, diferem entre si pelo teste Tukey.

a, c Means within a column with no common superscript differ significantly by Tukey test.

Tabela 5 - Interações entre período de arraçoamento e idade sobre o peso relativo do intestino e rendimento de carcaça. Cada valor representa a média \pm SEM

Table 5 - Interactions between feeding program and age on relative intestine weight and carcass yield. Each value represents the mean \pm SEM

\begin{tabular}{|c|c|c|c|c|}
\hline \multirow[t]{2}{*}{$\begin{array}{l}\text { Parâmetros } \\
\text { Parameters }\end{array}$} & \multirow[t]{2}{*}{$\begin{array}{l}\text { Programa alimentar } \\
\text { Feeding program }\end{array}$} & \multicolumn{3}{|c|}{$\begin{array}{c}\text { Idade (dias) } \\
\text { Age (days) }\end{array}$} \\
\hline & & 21 & 35 & 50 \\
\hline \multirow{5}{*}{$\begin{array}{l}\text { Peso do intestino }(\%) \\
\text { Intestine weight }\end{array}$} & Ad libitum & $6,82 \pm 0,16^{\mathrm{Ab}}$ & $5,35 \pm 0,20^{\mathrm{Bb}}$ & $3,73 \pm 0,11^{\mathrm{Cb}}$ \\
\hline & Arraçoamento noturno & $8,23 \pm 0,17^{\text {Аа }}$ & $6,11 \pm 0,19^{\mathrm{Ba}}$ & $4,25 \pm 0,16^{\mathrm{Ca}}$ \\
\hline & Nocturnalfeeding & & & \\
\hline & $\begin{array}{l}\text { Arraçoamento diurno } \\
\text { Diurnal feeding }\end{array}$ & $7,71 \pm 0,16^{\mathrm{Aa}}$ & $4,86 \pm 0,17^{\mathrm{Bb}}$ & $3,56 \pm 0,12^{\mathrm{Cb}}$ \\
\hline & Ad libitum & $71,99 \pm 0,60^{\mathrm{Ca}}$ & $74,94 \pm 0,48^{\mathrm{Ba}}$ & $78,74 \pm 0,36^{\mathrm{Aa}}$ \\
\hline \multirow{2}{*}{$\begin{array}{l}\text { Rendimento de carcaça }(\%) \\
\text { Carcass yield }\end{array}$} & Arraçoamento noturno & $68,28 \pm 0,43^{\mathrm{Cb}}$ & $71,20 \pm 0,77^{\mathrm{Bb}}$ & $77,29 \pm 0,39^{\mathrm{Aa}}$ \\
\hline & $\begin{array}{c}\text { Nocturnalfeeding } \\
\text { Arraçoamento diurno } \\
\text { Diurnalfeeding }\end{array}$ & $69,25 \pm 0,67^{\mathrm{Cb}}$ & $74,82 \pm 0,32^{\mathrm{Ba}}$ & $77,68 \pm 0,31^{\mathrm{Aa}}$ \\
\hline
\end{tabular}

aA,cC Médias seguidas por letras minúsculas (maiúsculas) diferentes, nas colunas (linhas), diferem entre si pelo teste Tukey.

$a A, c C$ Means followed by small (capital) letter in the same column (lines) differ significantly by Tukey test. 
Corless \& Sell (1999) reportaram que, jejum acima de 30 horas após o nascimento, reduzia o peso relativo do intestino delgado de perus. O atraso no desenvolvimento de todos os segmentos do intestino delgado devido ao jejum de alimento após o nascimento também foi observado por Uni et al. (1998). Em outro estudo, além da redução no peso das vísceras, Buhr et al. (1998) verificaram redução no diâmetro do jejuno e do íleo de frangos após 12 horas da retirada do alimento. Esse efeito sobre o peso do intestino pode estar diretamente relacionado com o maior ou menor desenvolvimento morfológico da mucosa intestinal (Uni et al., 1998). É conhecido que o epitélio intestinal é particularmente afetado pela ausência de alimento, sendo a altura das vilosidades significativamente reduzida em aves expostas ao jejum (Yamauchi et al., 1996). Por outro lado, Sklan \& Noy (2000) observaram que aves alimentadas aumentam a atividade enzimática na mucosa intestinal e correlacionaram esse fato ao peso do intestino e ao peso corporal. Embora o aumento no peso relativo do intestino, a partir do $35^{\circ}$ dia, possa ser interpretado como uma resposta compensatória para melhor absorção de nutrientes, essa não foi suficiente para compensar o período de 12 horas sem alimento, refletindo em menor peso vivo. Com relação ao rendimento de carcaça, houve aumento $(\mathrm{P}<0,01)$ com o crescimento dos frangos, não sendo verificadas, no entanto, diferenças $(\mathrm{P}>0,05)$ entre os períodos de arraçoamento aos 50 dias de idade (Tabela 5). Todos os parâmetros viscerais e o rendimento de carcaça foram afetados $(\mathrm{P}<0,01)$ pela idade das aves.

O programa alimentar afetou $(\mathrm{P}<0,01)$ os teores de proteína e gordura total da carcaça, porém não foi verificado efeito $(\mathrm{P}>0,05)$ sobre o teor de cinzas (Tabela 6). De acordo com as médias, aves arraçoadas no período noturno apresentaram maior teor de gordura corporal e menor teor de proteína do que as aves arraçoadas ad libitum; no entanto, não diferiram ( $\mathrm{P}>0,05)$ dos animais arraçoados no período diurno. Com o crescimento das aves, houve redução $(\mathrm{P}<0,01)$ na quantidade de proteína e cinzas e aumento $(\mathrm{P}<0,01)$ na gordura total da carcaça.

A técnica de restrição alimentar tem sido estudada

Tabela 6 -Efeitos do período de arraçoamento e da idade sobre a composição corporal dos frangos. Cada valor representa a média \pm SEM

Table 6 - Effects of feeding program and age on broiler carcass composition. Each value represents the mean \pm SEM

\begin{tabular}{|c|c|c|c|}
\hline & \multicolumn{3}{|c|}{$\begin{array}{c}\text { Parâmetros } \\
\text { Parameter }\end{array}$} \\
\hline & $\begin{array}{l}\text { Proteína } \\
\text { Protein } \\
---------\end{array}$ & $\begin{array}{l}\text { Gordura total } \\
\text { Carcass fat } \\
\quad(\%)-\end{array}$ & $\begin{array}{c}\text { Cinzas } \\
\text { Ash } \\
---\end{array}$ \\
\hline \multicolumn{4}{|l|}{ Programa alimentar } \\
\hline \multicolumn{4}{|l|}{ Feeding program } \\
\hline Ad libitum & $51,56 \pm 0,67^{\mathrm{a}}$ & $36,99 \pm 1,18^{b}$ & $8,17 \pm 0,31$ \\
\hline Arraçoamento noturno & $49,74 \pm 0,75^{\mathrm{b}}$ & $39,89 \pm 1,11^{\mathrm{a}}$ & $8,02 \pm 0,20$ \\
\hline \multicolumn{4}{|l|}{ Nocturnal feeding } \\
\hline Arraçoamento diurno & $50,32 \pm 0,61^{\mathrm{ab}}$ & $38,06 \pm 1,20^{\mathrm{a}}$ & $7,99 \pm 0,22$ \\
\hline \multicolumn{4}{|l|}{ Diurnalfeeding } \\
\hline \multicolumn{4}{|l|}{ Idade (dias) } \\
\hline \multicolumn{4}{|l|}{ Age (days) } \\
\hline 21 & $54,25 \pm 0,38^{\mathrm{a}}$ & $31,78 \pm 0,72^{c}$ & $8,15 \pm 0,28^{a}$ \\
\hline 35 & $49,45 \pm 0,46^{\mathrm{b}}$ & $40,55 \pm 0,71^{b}$ & $8,41 \pm 0,17^{\mathrm{a}}$ \\
\hline 50 & $47,28 \pm 0,39^{\mathrm{c}}$ & $43,61 \pm 0,64^{\mathrm{a}}$ & $7,52 \pm 0,19^{b}$ \\
\hline \multicolumn{4}{|l|}{ Probabilidades } \\
\hline \multicolumn{4}{|l|}{ Probabilities } \\
\hline \multicolumn{4}{|l|}{ Programa alimentar (PA) } \\
\hline Feeding program $(F P)$ & $<0,01$ & $<0,05$ & NS \\
\hline \multicolumn{4}{|l|}{ Idade (I) } \\
\hline Age $(A)$ & $<0,01$ & $<0,01$ & $<0,01$ \\
\hline \multicolumn{4}{|l|}{ PA x I } \\
\hline$F P \times A$ & NS & NS & NS \\
\hline
\end{tabular}

${ }^{a-c}$ Médias seguidas por letras diferentes, nas colunas, diferem entre si pelo teste Tukey.

a.c Means within a column with no common superscript differ significantly by Tukey test.

R. Bras. Zootec., v.31, n.6, p.2265-2273, 2002 
no sentido de se obterem carcaças de frangos com menores teores de gordura e maiores de proteína, tornando o produto mais saudável. Segundo Evans (1977), a gordura abdominal é mais diretamente influenciada pela nutrição do que a gordura total da carcaça, cuja quantidade é principalmente determinada pelo fator genético. Além desse fato, trabalhos têm sugerido uma alta atividade lipogênica em frangos após a restrição alimentar, quando comparados com animais alimentados ad libitum (Furlan, 1996). Nesse sentido, Donaldson (1990) observou que a atividade enzimática das células hepáticas de frangos restrito-realimentados foi de 2 a 3 vezes maior do que a de frangos alimentados à vontade. Aumento nos níveis de enzimas lipogênicas em frangos restritos, durante a primeira semana de realimentação também foram observados por Rosebrough et al. (1986). Os resultados de adiposidade sugerem que, mesmo após um curto período de restrição alimentar (12 horas), o frango restrito procurou repor rapidamente a energia utilizada durante o período sem alimento, aumentando a lipogênese e o armazenamento de energia.

\section{Conclusões}

A forma de arraçoamento por 12 horas, tanto diurna quanto noturna, não se mostrou satisfatória no manejo diário, uma vez que houve prejuízo no desempenho produtivo com menor peso vivo e maior teor de gordura na carcaça.

\section{Literatura Citada}

BARASH, I.; NITSAN, Z.; NIR, I. Adaptation of light-bodied chicks to meal feeding:gastrointestinal tract and pancreatic enzymes. British Poultry Science, v.34, n.1, p.35-42, 1993.

BUHR, R.J.; NORTHCUTT, J.K.; LYON, C.E. et al. Influence of time off feed on broiler viscera weight, diameter, and shear. Poultry Science, v.77, n.5, p.758-764, 1998.

BUYSE, J.; ADELSOHN, D.S.; DECUYPERE, E. et al. Diurnalnocturnal changes in food intake, gut storage of ingesta, food transit time and metabolism in growing broiler chickens: a model for temporal control of energy balance. British Poultry Science, v 34, n.4, p.699-709, 1993.

CORLESS, A.B.; SELL, J.L. The effects of delayed access to feed and water on the physical and functional development of the digestive system of young turkeys. Poultry Science, v.78, n.8, p.1158-1169, 1999.

CHERRY, J.A.; SIEGEL, P.B. Selection for body weight at eight weeks of age. Feed passage and intestinal size of normal and dwarf chickens. Poultry Science, v.57, n.2, p.336-340, 1978.

DONALDSON, W.E. Lipid metabolism in liver of chicks: Response to feeding. Poultry Science, v.69, n.7, p.1183-1187, 1990.
EVANS, A.J. The growth of fat. In: BOORMAN, K.N.; WILSON, B.J. (Eds.) Growth and poultry meat production. Edinburgh: British Poultry Science, 1977. p.29-64.

FURLAN, R.L. Efeito da restrição alimentar sobre o crescimento e composição da carcaça de frangos de corte. Jaboticabal: Universidade Estadual Paulista, 1996. 102p. Tese (Doutorado em Zootecnia) - Universidade Estadual Paulista, 1996.

GIACHETTO, P.F. Mecanismos hormonais do ganho compensatório e composição de carcaça em frangos de corte submetidos a restrição alimentar com diferentes níveis energéticos. Jaboticabal: Universidade Estadual Paulista, 1998. 98p. Dissertação (Mestrado em Zootecnia) Universidade Estadual Paulista, 1998.

GONZALES, E.; JUNQUEIRA, O.M.; MACARI, M. et al. Uso da restrição alimentar quantitativa para diminuir a mortalidade de frangos de corte machos. Revista Brasileira de Zootecnia, v.27, n.1, p.129-136, 1998.

LANARA - LABORATÓRIO NACIONAL DE REFERÊNCIA ANIMAL. Métodos de análises oficiais par controle de produtos de origem animal e seus ingredientes. Brasília, DF, 1981.

LIPPENS, M.; ROOM, G.; De GROOTE, G. et al. Early and temporary quantitative food restriction of broiler chickens. 1. Effects on performance characteristics, mortality and meat quality. British Poultry Science, v.41, n.2, p.343-354, 2000.

PLAVNIK, I.; HURWITZ, S. The performance of broiler chicks during and following a severe feed restriction at an early age. Poultry Science, v.64, n.2, p.348-355, 1985.

PLAVNIK, I.; MCMURTRY, J.P.; ROSEBROUGH, R.W. Effect of early feed restriction in broilers. I. Growth performance and carcass composition. Growth, v.50, p.68-76, 1986.

PLAVNIK, I.; HURWITZ, S. Response of broiler chickens and turkey poults to food restriction of varied severity during early life. British Poultry Science, v.32, n.2, p.343-352, 1991.

ROBINSON, F.E.; CLASSEN, H.L.; HANSON, J.A. et al. Growth performance, feed efficiency and the incidence of skeletal and metabolic disease in full-fed and feed restricted broiler and roaster chickens. Journal of Applied Poultry Research, v.1, n.1, p.33-41, 1992.

ROSEBROUGH, R.W.; STEELE, N. C.; MCMURTRY, J.P. et al. Effect of early feed restriction in broilers. II. Lipid metabolism. Growth, v.50, p.217-227, 1986.

SAS INSTITUTE Statistical Analysis System. Users guide. Cary: 2000.

SKLAN, D.; NOY, Y.; HOYZNAN, A. et al. Decreasing weight loss in the hatchery by feeding chicks and pouts in hatchery trays. Journal of Applied Poultry Research, v.9, n.1, p.142-148, 2000.

SKLAN, D.; NOY, Y. Hydrolysis and absorption in the small intestines of post-hatch chicks. Poultry Science, v.79, n.11, p.1306-1310, 2000.

SUSBILLA, J.P.; FRANKEL, T.L.; PARKINSON, G. et al. Weight of internal organs and carcasses yield of early food restricted broilers. British Poultry Science, v.35, n.5, p.677-685, 1994.

UNI, Z.; GANOT, S.; SKLAN, D. Posthatch development of mucosal function in the broiler small intestine. Poultry Science, v.77, n.1, p.75-82, 1998.

WILSON, P.N.; OSBOURN, D.F. Compensatory growth after undernutrition in mammals and birds. Biological Reviews, v.35, p.324-363, 1960. 
YAMAUCHI, K.; KAMISOYAMA, H.; ISSHIKI, Y. Effects of fasting and refeeding on structures of the intestinal villi and epithelial cells in white leghorn hens. British Poultry Science, v.37, n.5, p.909-921, 1996.

YU, M.W.; ROBINSON, F.E.; CLANDINI, M.T. et al. Growth and body composition of broiler chickens in response to different regimens of feed restriction. Poultry Science, v.69, n.12, p.2074-2081, 1990.

YU, M.W.; ROBINSON, F.E.. The application of shortterm feed restriction to broilers chickens production: a review. Journal of Applied Poultry Research, v.1, n.1, p.147-153, 1992.
ZUBAIR, A.K.; LEESON, S. Effect of varying period of early nutrient restriction on growth compensation and carcass characteristics of male broilers. Poultry Science, v.73, n.1, p.129-136, 1994.

ZUBAIR, A.K., LEESON, S. Compensatory growth in the broiler chickens: a review. World's Poultry Science Journal, v.52, n.2, p.189-201, 1996.

Recebido em: 10/10/01

Aceito em: 15/04/02 